\title{
Online Cooperative Promotion and Cost Sharing Policy under Supply Chain Competition
}

\author{
Erjiang E, ${ }^{1}$ Geng Peng, ${ }^{1,2}$ Xin Tian,, ${ }^{1,2,3}$ and Qinghong Chen ${ }^{4}$ \\ ${ }^{1}$ School of Economics and Management, University of Chinese Academy of Sciences, Beijing 100190, China \\ ${ }^{2}$ Key Laboratory of Big Data Mining and Knowledge Managements, Chinese Academy of Sciences, Beijing 100190, China \\ ${ }^{3}$ Research Center on Fictitious Economy \& Data Science, Chinese Academy of Sciences, Beijing 100190, China \\ ${ }^{4}$ Shanghai HEADING Information Engineering Co., Ltd., Shanghai 201112, China
}

Correspondence should be addressed to Xin Tian; tianx@ucas.ac.cn

Received 30 December 2015; Accepted 2 February 2016

Academic Editor: Mohammed Nouari

Copyright (C) 2016 Erjiang E et al. This is an open access article distributed under the Creative Commons Attribution License, which permits unrestricted use, distribution, and reproduction in any medium, provided the original work is properly cited.

\begin{abstract}
This paper studies online cooperative promotion and cost sharing decisions in competing supply chains. We consider a model of one B2C e-commerce platform and two supply chains each consisting of a supplier and an online retailer. The problem is studied using a multistage game. Firstly, the e-commerce platform carries out the cooperative promotion and sets the magnitude of markdown (the value of e-coupon). Secondly, each retailer and his supplier determine the fraction of promotional cost sharing when they have different bargaining power. Lastly, the retailers decide whether to participate in the cooperative promotion campaign. We show that the retailers are likely to participate in the promotion if consumers become more price-sensitive. However, it does not imply that the retailers can benefit from the price promotion; the promotion decision game resembles the classical prisoner's dilemma game. The retailers and suppliers can benefit from the cooperative promotion by designing an appropriate cost sharing contract. For a supply chain, the bargaining power between supplier and retailer, consumer price sensitivity, and competition intensity affect the fraction of the promotional cost sharing. We also find that equilibrium value of e-coupon set by the e-commerce platform is not optimal for all the parties.
\end{abstract}

\section{Introduction}

The Internet has reduced barriers to information coupling, and buyers have much easier access to the information of products and a great number of potential suppliers; price competition among sellers has become more intense $[1,2]$. According to 2012 Development Report on China Retailing Industry, the price war among B2C (Business to Customer) e-commerce companies was carried out nine times in 2012 (Source: The website of the Ministry of Commerce of the People's Republic of China, http://tfzs.mofcom.gov.cn/ article/date/201307/20130700186593.shtml). The difficulty does not appear to be with the transaction volume but with the problem of transaction profitability with low returns to online retailers [3]. Price competition may boost demand, but it also cuts the product profitability for a firm.

In recent years, cooperative promotion carried out by cross brands has become more common in the online retail industry. Brynjolfsson et al. [4] argue that increasing product variety made available through electronic markets can be a significantly larger source of consumer surplus gains. For instance, the daily sales of T-mall (the largest B2C ecommerce company in China) on the Singles Day (the largest online shopping day in China) grew from $\$ 5.8$ billion in 2013 to $\$ 9.3$ billion in 2014. In order to gain a bigger share of the retail market, increasing e-commerce firms, such as JD and Amazon, and online stores choose to participate in cooperative promotional activities. For online stores in a common platform, providing customers with the same discounts or e-coupon is a popular marketing strategy on the cooperative promotion campaign. In 2014, for example, T-mall worked with some online medical retailers who have high market shares to carry out the cooperative promotional activity. They provided customers with $10 \mathrm{CNY}$ e-coupons (about 1.6 dollars) on the Singles Day. Customers can use this e-coupon to buy the products of the online stores which 
participate in the promotion. Nevertheless, these online retailers compete against each other in the common market, and consumers have different price sensitivity in different products. During the promotion period, therefore, the sales and profits of online retailers would be different. Consumer price sensitivity directly affects a firm's pricing strategies and profits [5]. These medical retailers communicated with the upstream suppliers and required suppliers to share part of promotion costs. As a result, a small number of suppliers promised to bear all promotion costs and some others were willing to share part of the costs, but there were some suppliers that refuse to share these costs. These online retailers faced the problems of whether to participate in this cooperative promotional activity.

For a firm, whether promotion should be attended depends on whether it generates a positive value (i.e., incremental profit). In this paper, we consider supply chains that compete with one another, and we seek to investigate how promotion decisions depend on consumer price sensitivity, competition intensity, and the magnitude of the markdown. We also examine how the cost sharing policy in a supply chain is affected by the bargaining power, consumer price sensitivity, and competition intensity.

We focus on a model of one B2C e-commerce platform and two supply chains each consisting of a supplier and an online retailer. The retailers compete by selling partially substitutable products in a common e-commerce platform. Some empirical studies show that consumers are more pricesensitive during periods of high demand such as Christmas and Thanksgiving [6-8]. This view also applies to the online purchasers in the online shopping holiday. Consumers' price sensitivity was uncertain during the cooperative promotion period, and this state is observable by both retailers but not the suppliers. The e-commerce platform organizes the retailers to carry out the cooperative promotion campaign. Each retailer and his supplier decide whether to participate in the promotion and share the promotion cost, respectively. Although the case of only two supply chains is a simplification of reality, it is sufficient to capture the main issue of online cooperative promotion.

We use a multistage game to study the firms' equilibrium promotion decisions. In the beginning, the e-commerce platform sets the magnitude of markdown (the value of e-coupon) to induce the retailers to participate in the promotion. Next, each retailer shares the information of consumers' price sensitivity with his supplier and requires his supplier to share the promotion cost. Then, each supplier offers an amount of cost sharing to her retailer based on the expected profits and bargaining power. After learning the payment offered by his supplier, each retailer decides either to participate in the promotion or not based on the expected sales and profits. We first analyze the retailers' promotion arrangement without the suppliers' support (i.e., there is no cost sharing policy). We show that the retailers may change their decisions from no participation to participation when consumers become more price-sensitive or competition becomes more intense. We then analyze the effect of cost sharing policy in a supply chain. We find that price sensitivity, competition intense, profit margins, and bargaining power affect the fraction of promotional cost sharing for a supply chain. Finally we analyze how the ecommerce platform obtains the profit as much as possible by setting the magnitude of markdown (the value of e-coupon). We show that a supply chain with higher profit margins may be better off when consumers become more price-sensitive or competition less intense. We also find that the equilibrium value of e-coupon set by the e-commerce platform is not optimal for all the parties.

The rest of this paper is organized as follows. Section 2 provides a literature review. Section 3 describes the model. Section 4 investigates supply chains' cost sharing policy and promotion equilibrium decisions and studies the optimal value of e-coupon. Section 5 presents some numerical examples. Finally, Section 6 summarizes our results. The proofs of formal results are given in the Appendix.

\section{A Literature Review}

Our study is closely related to three areas: consumer price sensitivity and promotion, supply chain coordination, and supply chain competition.

This paper is most related to the literature which studies the relationship between consumer price sensitivity and promotion. One stream of research evaluates the change of consumers' price sensitivity in the promotion activity [9-11]. Mela et al. [12] argue that consumers might become more price-sensitive with an increase in the frequency of discounts. Frequent price promotions, however, might depress sales because consumers expect a lower price in the future. There is a nonlinear relationship between the frequency of discounts and consumers' price sensitivity [13]. Han et al. [14] used an approach that incorporates probabilistic thresholds to examine consumers' price sensitivity and find that intense price promotion by competing brands makes consumers more sensitive to losses but not influence consumers' sensitivity to gains. Another stream of research more relevant to our work investigates the impact of consumers' price sensitivity on firms' promotion strategy. Kopalle et al. [15] proposed the dynamic effect of discounts on the sales. They advise that if deals become more effective in the current period, that is, if consumers are more price sensitive, promotions should be used more frequently, and as the negative dynamic effect of discounts the optimal level of discounting should go down. Kalyanaram and Winer [16] examined the relationship between consumer reference price and promotion and find that an increase in discounts may reduce consumers' reference prices and perhaps harming brand equity. Kogan and Herbon [17] investigated the effect of customer price sensitivity for supply chain's profit under a limited-time promotion. Then they find that the promotion is not always beneficial if customer sensitivity increases. Based on the above literature, we examine how supply chains' promotion decisions and cost sharing policy depend on consumers' price sensitivity. With the emergence of new promotion forms, such as group-buying and free shipping, some scholars began to study e-consumer buying behavior on the online promotion [18-20]. Little attention has been given to the consumer price sensitivity in the cooperative promotion 
activity. One contribution, considering the effect of consumer price sensitivity in competing supply chains, is made by our paper.

Contracts of cost sharing or revenue-sharing in supply chains have been studied extensively. A substantial amount of work in this literature considers supply chains' coordination under different situation [21, 22]. Cachon and Lariviere [23] compared revenue-sharing to a number of other supply chain contracts, such as buy-back contracts and price discount contracts, and then analyzed the strengths and limitations of the revenue-sharing contract in supply chain coordination. Yao et al. [24] studied a revenue-sharing contract for a supply chain consisting of one manufacturer and two competing retailers. They show that the provision of revenue-sharing in the contract can obtain better performance than a priceonly contract. Tsao and Sheen [25] argue that the sales learning curve of retailers should be taken into account. Dana and Spier [26] examined the effectiveness of the revenuesharing contract in vertically separated industries when there is intrabrand competition among the downstream firms and find that revenue-sharing is a valuable instrument. Li et al. [27] considered a supply chain consisting of one retailer and two competing suppliers under an environment of supply disruption and devise a coordination mechanism (Nash bargaining game) to maximize the profits of both suppliers. We make a contribution to this literature by considering supply chains' coordination with cost sharing policy in a competitive environment.

Currently, it is no longer a firm versus a firm but rather a supply chain versus a supply chain in the competition for many marketplaces [28]. Increasing attention has been paid to the issues of supply chain competition. The existing work on supply chain competition can be divided into two categories. The first is that how channel structure depends on competition intensity and the type of competition $[29,30]$. McGuire and Staelin [31] considered a model of vertical distribution structures with two manufactures and two exclusive retailers. They investigated the effect of product substitutability and find that manufacturers will be more likely to use a decentralized distribution system for the more highly competitive goods. Coughlan [32] analyzed the issue of choosing marketing channel in a duopoly market, and the results are applied to the international semiconductor industry. Ha et al. [33] investigated how supply chain's information sharing decisions depend upon production diseconomies of scale, information accuracy, competition intensity, and the type of competition. The second is that how the contract design is affected by the uncertainty of demand or supply [34-36]. Ai et al. [37] investigated a full-returns policy of competing supply chain with demand uncertainty. Demirag et al. [38] analyzed the performance of customer rebate and retailer incentive promotions under supply chain competition. Ha and Tong [39] analyzed the information sharing strategies of two competing supply chains in the cases of contract menus and linear price contracts. In addition, Cheng [40] proposed the concept of virtual business. He suggests that a production chain and a supply chain should be combined by using the cloud computing, Internet of Things, big data, and other advanced information technologies. In this way,

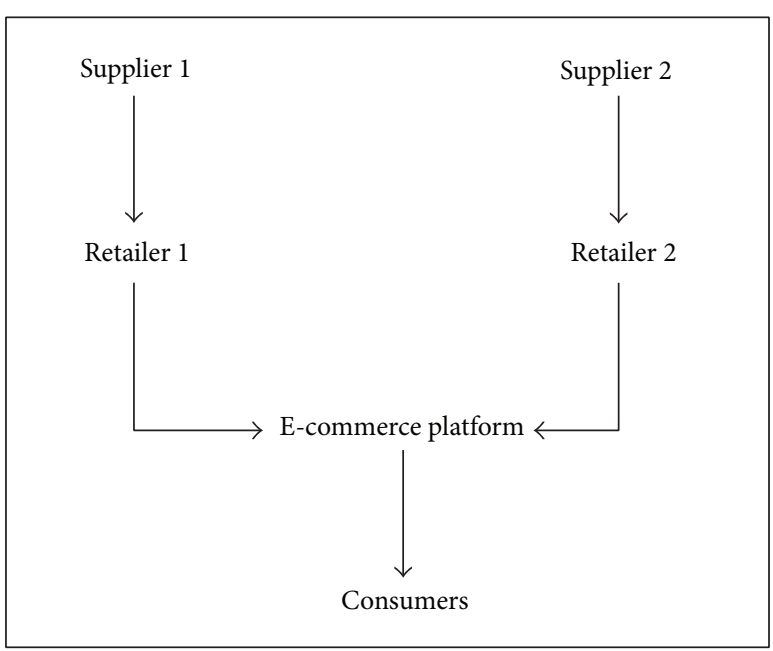

FIGURE 1: The relationship between supply chains.

the situation of overall optimization can be realized in the industry chain including production chain and supply chain. They also explicitly mention supply chain coordination in the competitive environment but do not discuss the problem of supply chain coordination in a cooperative promotion campaign.

\section{Model}

Consider two supply chains, each consisting of one supplier selling a partially substitutable product to one online retailer. The retailers compete in a common e-commerce market. The suppliers, the retailers, and the supply chains are indexed by $i=1,2$. Figure 1 illustrates the relationship between supply chains in this paper.

The timing of the game is as follows. In the first stage, the e-commerce platform organizes the cooperative promotion campaign and sets the magnitude of markdown (such as unified e-coupon for all retailers). In the second stage, each retailer and his supplier determine the fraction of promotional cost sharing. In the last stage, the retailers decide whether to participate in the cooperative promotion campaign. We solve the game backward for its subgameperfect Nash equilibrium in the Section 4.

3.1. Basic Model. The demand function for retailer $i$ is given by

$$
\begin{array}{r}
q_{i}=a_{i}+b_{i}\left(P_{i}-p_{i}\right)-d_{i}\left(P_{j}-p_{j}\right) \\
\quad(i=1,2 ; j=3-i) .
\end{array}
$$

Normally, retailer $i$ sells the goods with customers at the list price $P_{i}$, and his competitor (retailer $j$ ) sells the partially substitutable product at the list price $P_{j}$. In the price promotion period, decision variables $p_{i}$ and $p_{j}$ correspond, respectively, to the promotion price for retailer $i$ and $j$. Parameters $b_{i}$ and $d_{i}$ indicate consumers' price sensitivity and competition intensity for retailer $i$, respectively, $b_{i}>d_{i}$. Thus 
TABLE 1: The payoff matrix of two retailers.

Retailer 2

No participation $\left(X_{2}=N\right)$ Participation $\left(X_{2}=Y\right)$

Retailer 1

No participation $\left(X_{1}=N\right)$

Participation $\left(X_{1}=Y\right)$

$$
\left(\pi_{r 1}^{N, N}, \pi_{r 2}^{N, N}\right)
$$

$\left(\pi_{r 1}^{N, Y}, \pi_{r 2}^{Y, N}\right)$

$\left(\pi_{r 1}^{Y, N}, \pi_{r 2}^{N, Y}\right)$

$\left(\pi_{r 1}^{Y, Y}, \pi_{r 2}^{Y, Y}\right)$

$a_{i}$ is the demand under anticipated list pricing if retailer $i$ and her competitor do not carry out price promotion activity, $P_{i}=p_{i}, P_{j}=p_{j}$. Our demand function is similar to Kogan and Herbon [17], but they did not consider the influence from the competitor, $d_{i}\left(P_{j}-p_{j}\right)$. Through a simple transform, the demand function can be rewritten as

$$
q_{i}=g_{i}-b_{i} p_{i}+d_{i} p_{j}
$$

The demand potential for retailer $i$ is $g_{i}$, where $g_{i}=a_{i}+$ $b_{i} P_{i}-d_{i} P_{j}$. This is a classical Bertrand retail competition. Since consumers have different sensitivity in different products, it means $b_{i} \neq b_{j}$. In order to describe how the sales of retailers affected by the difference of price sensitivity, we assume that

$$
d_{i}=k_{i} b_{j}
$$

This equation indicates that the sales of retailer $i$ would be influenced by the price sensitivity of his competitor (i.e., larger or smaller $b_{j}$ ). Parameter $k_{i}$ can be defined as the influence coefficient, $0<k_{i}<b_{i} / b_{j}$.

3.2. E-Commerce Platform's Problem. For an e-commerce platform, extracting a percentage of the commission from the online retailers' revenues is the main source of income. Thus the profit function for the e-commerce platform is given by

$$
\pi_{e}=\phi \sum_{i=1}^{2}\left[a_{i}+b_{i}\left(P_{i}-p_{i}\right)-k_{i} b_{j}\left(P_{j}-p_{j}\right)\right] p_{i}-c_{e}
$$

Parameter $\phi$ represents the percentage of commission on the revenues of retailers. The operating cost is constant $c_{e}$ for the e-commerce platform. Now the e-commerce platform sets the magnitude of markdown (the value of e-coupon) to induce the retailers to participate in the cooperative promotion. Consumers can use the e-coupon to buy the products of retailers without being limited by the purchase amount. Let $V$ be the value of e-coupon to consumers, $V \geq 0$. If retailer $i$ chooses to participate in the promotion, we have $P_{i}-p_{i}=V$. Hence, the profit function of the e-commerce platform can be expressed as

$$
\pi_{e}=\phi \sum_{i=1}^{2}\left(a_{i}+b_{i} V-k_{i} b_{j} V\right)\left(P_{i}-V\right)-c_{e}
$$

Given any retail price $P_{i}$ set by retailer $i$ and fixed parameter $\phi$, the e-commerce platform maximizes its expected profit by setting the value of e-coupon $V$. Note that, the demand states of the retailers are also observable by e-commerce platform.
3.3. Retailers' Problem. The retailers maximize expected profits by deciding whether to participate in promotion and demanding the suppliers to bear part of the promotion cost. Retailer $i$ makes a promotion arrangement in the last stage, which we denote by $X_{i}=Y$ (participation) or $N$ (not participation). The promotion arrangement $X_{i}$ in retailer $i$ is unknown to his competitor (retailer $j$ ). During the promotion period, the profit function of retailer $i$ is

$$
\begin{aligned}
& \pi_{r i}^{X_{i}, X_{j}} \\
& \quad=\left(a_{i}+b_{i} V-k_{i} b_{j} V\right)\left[(1-\phi)\left(P_{i}-V\right)-w_{i}+S_{i}\right] .
\end{aligned}
$$

The fraction of promotional cost sharing offered by supplier $i$ is denoted by $S_{i}$, and the wholesale price for retailer $i$ is $w_{i}$. The superscripts of $\pi_{r i}^{X_{i}, X_{j}}$ indicate the dependency of retailer $i$ 's decision on the promotion arrangements in both supply chains, where the first superscript refers to the arrangement in retailer $i$ and the second superscript represents the arrangement of the rival retailer. For example, $\pi_{r 1}^{Y, N}$ denotes the profits of retailer 1 when he chooses to participate in the promotion and retailer 2 does not participate in the promotion. Based on the strategy combinations of the retailers, we obtain the payoff matrix of retailers as shown in Table 1.

3.4. Suppliers' Problem. The suppliers also want to maximize expected profits by selecting proper fraction of promotional cost sharing. The profit function for supplier $i$ is given by

$$
\pi_{s i}^{X_{i}, X_{j}}=\left(a_{i}+b_{i} V-k_{i} b_{j} V\right)\left(w_{i}-c_{s i}-S_{i}\right) .
$$

The unit purchase costs incurred by supplier $i$ are denoted by $c_{s i}$. We do not consider the retailers' inventory here. The profit function for supply chain $i$ is

$$
\begin{aligned}
\pi_{i}^{X_{i}, X_{j}} & =\pi_{r i}^{X_{i}, X_{j}}+\pi_{s i}^{X_{i}, X_{j}} \\
& =\left(a_{i}+b_{i} V-k_{i} b_{j} V\right)\left[(1-\phi)\left(P_{i}-V\right)-c_{s i}\right] .
\end{aligned}
$$

\section{Model Analysis and Solution}

In this section, we first analyze the situation that each retailer bears the promotional cost without his suppliers' support and makes promotion decisions based on consumers' price sensitivity, competition intensity, and competitor's reaction. Secondly, the effect of cost sharing policy on the promotion would be investigated. Finally, we analyze how the ecommerce platform obtains the profits as much as possible by setting the value of e-coupon. Meanwhile, the optimal value of e-coupon for all the parties will also be explored. 
4.1. Promotion Decisions without Suppliers' Support. In order to study how consumer price sensitivity and competition intensity affect the promotion decisions of retailers, we assume each supplier does not share any promotion cost (also called decentralized decision). The retailers' profits are calculated based on the expected price sensitivity and competition intensity. Here we assume that a retailer will choose to participate in the promotion if he is indifferent between participation and not participation. According to (6), retailer $i$ will choose to participate in the promotion if $\pi_{r i}^{Y, X_{j}} \geq \pi_{r i}^{N, X_{j}}$. Hence, the lower bound of consumer price sensitivity for retailer $i$ is given by

$$
\begin{aligned}
& b_{i} \geq L_{i 1}^{D}=\frac{(1-\phi)\left(a_{i}-k_{i} b_{j} V\right)}{(1-\phi)\left(P_{i}-V\right)-w_{i}} \text { or } \\
& b_{i} \geq L_{i 2}^{D}=\frac{(1-\phi) a_{i}}{(1-\phi)\left(P_{i}-V\right)-w_{i}} .
\end{aligned}
$$

The symbols $L_{i 1}^{D}$ and $L_{i 2}^{D}$ denote the lower bound of consumer price sensitivity when rival retailer $j$ chooses to participate in the promotion and when not participating, respectively. It is easy to see that $L_{i 1}^{D}<L_{i 2}^{D}(i=1,2)$.

Lemma 1. Suppose each supplier $i(i=1,2)$ does not share promotion cost, $S_{i}=0$. (a) If $b_{i} \geq L_{i 2}^{D}, Y$ is the dominant strategy for retailer $i$. (b) If $b_{i} \in\left[L_{i 1}^{D}, L_{i 2}^{D}\right), Y$ is the optimal strategy for retailer $i$ when his competitor chooses $Y$; and $N$ is the optimal strategy when his competitor chooses $N$. (c) If $b_{i}<L_{i 1}^{D}, N$ is the dominant strategy for retailer $i$.

The retailers' promotion decisions would be affected by the intensity of market competition. The promotion decisions of retailer $i$ may change from $N$ (not participation) to $Y$ (participation) when competition becomes more intense (larger $\left.k_{i}\right)$. The equilibrium promotion decisions $\left(X_{1}^{*}, X_{2}^{*}\right)$ are driven by consumers' price sensitivity and can be characterized as follows.

Theorem 2. Suppose both suppliers do not share promotion cost, $S_{1}=S_{2}=0$. (a) If $b_{1} \geq L_{12}^{D}$ and $b_{2} \geq L_{22}^{D},(Y, Y)$ is the unique equilibrium. (b) If $b_{1} \in\left[L_{11}^{D}, L_{12}^{D}\right)$ and $b_{2} \in\left[L_{21}^{D}, L_{22}^{D}\right)$, $(Y, Y)$ and $(N, N)$ are the (only) two equilibria, but $(N, N)$ is Pareto optimality. (c) If $b_{1}<L_{11}^{D}$ and $b_{2}<L_{21}^{D},(N, N)$ is the unique equilibrium; (d) if $b_{1}<L_{11}^{D}$ and $b_{2} \geq L_{22}^{D},(N, Y)$ is the unique equilibrium. (e) If $b_{1} \in\left[L_{11}^{D}, L_{12}^{D}\right)$ and $b_{2}<L_{21}^{D}$, $(N, N)$ is the unique equilibrium. ( $f$ ) If $b_{1} \in\left[L_{11}^{D}, L_{12}^{D}\right)$ and $b_{2} \geq L_{22}^{D}$, $(Y, Y)$ is the unique equilibrium.

The results in Theorem 2 are illustrated in Figure 2. The intensity of competition in the market directly affects the equilibrium promotion decision. The dashed lines, $L_{11}^{D}$ and $L_{21}^{D}$, shift to the lower left corner as competition becomes more intense (larger $k_{i}$ ). At the same time, the solid lines, $b_{2}=$ $k_{2} b_{1}$ and $b_{2}=k_{1}^{-1} b_{1}$, shift upward and downward, respectively. The equilibrium may change from $(Y, N)$ to $(Y, Y)$ as the curve $L_{21}^{D}$ or $L_{11}^{D}$ shifts downward. It is worth mentioning that when

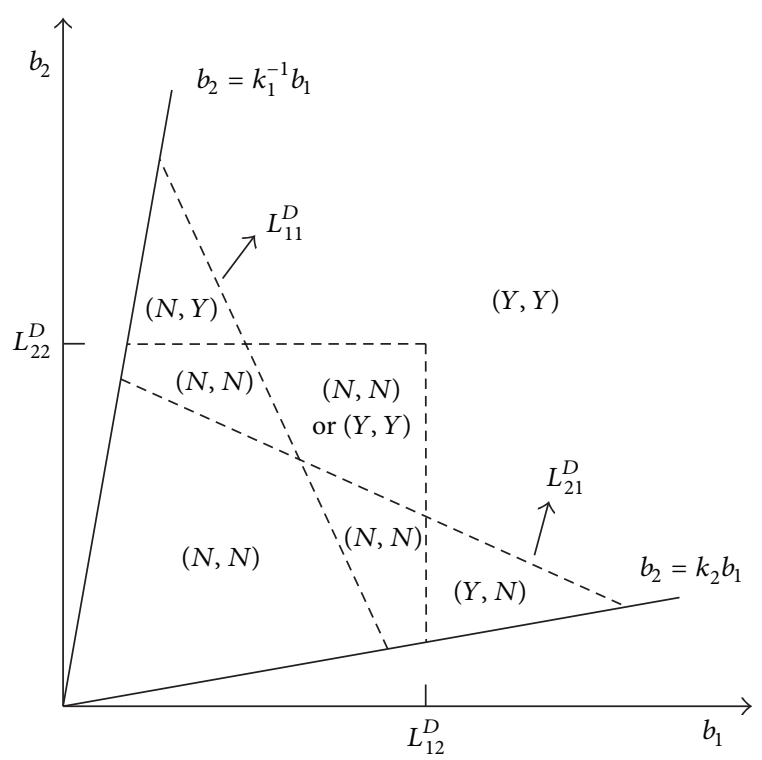

FIGURE 2: Equilibrium promotion decisions for two retailers.

$L_{i 2}^{D} \leq b_{i}<L_{i 2}^{D}+k_{i} b_{j}$, the dominant strategy for retailer $i(i=1,2)$ is to participate in the promotion; $(Y, Y)$ is the unique equilibrium, but both retailers would be better off at $(N, N)$. Under certain parametric conditions, the promotion game resembles the classical prisoner's dilemma game.

Corollary 3. Suppose both suppliers do not share promotion costs, $S_{1}=S_{2}=0$. If $b_{1} \geq L_{12}^{D}+k_{1} b_{2}$ and $b_{2} \geq L_{22}^{D}+k_{2} b_{1},(Y, Y)$ is the unique equilibrium, and $\pi_{r 1}^{Y, Y}>\pi_{r 1}^{N, N}, \pi_{r 2}^{Y, Y}>\pi_{r 2}^{N, N}$, and the prisoner's dilemma was dissolved.

The implication of Corollary 3 is that the degree of product's heterogeneity should be increased for a supply chain. In this way, the supply chain can benefit from the price promotion if consumers are more price-sensitive for his product (larger $b_{i}$ ) or the influence of competitors can be reduced (smaller $k_{i}$ ).

4.2. The Effect of Cost Sharing Policy on the Promotion. In this subsection, we examine the effect of cost sharing policy on the promotion for a supply chain (also called centralized decision). Whether the promotion cost will be shared depends on whether promotion generates a positive value (i.e., incremental profit) for a supply chain. According to (7), there is a negative correlation between the suppliers' profits and the amount of cost sharing. Here we assume a supplier will agree to share promotion cost if she is indifferent between sharing and not sharing. Supplier $i$ will choose to share the promotion cost if and only if $\pi_{s i}^{Y, X_{j}} \geq \pi_{s i}^{N, X_{j}}$. Thus, the upper bound of the fraction of the promotional cost sharing for supplier $i$ is given by

$$
S_{i}^{\max }=\frac{\left(w_{i}-c_{s i}\right) b_{i} V}{a_{i}+b_{i} V-k_{i} b_{j} V} .
$$


And the lower bound of the fraction of the promotion cost sharing for supplier $i$ is given by

$$
S_{i}^{\min }=\frac{(1-\phi)\left[a_{i}-b_{i}\left(P_{i}-V\right)-k_{i} b_{j} V\right] V+b_{i} w_{i} V}{a_{i}+b_{i} V-k_{i} b_{j} V} .
$$

Theorem 4. When retailer $j$ chooses to participate in the promotion, the upper bound of the fraction of the promotional cost sharing for supplier i is $S_{i}^{\max }$; the lower bound of the fraction of the promotional cost sharing for supplier $i$ is $S_{i}^{\mathrm{min}}$.

From the results of Theorem 4, a higher profit margin means the stronger capability of cost sharing for a supplier (larger $\left.S_{i}^{\max }\right)$. Because of $\partial S_{i}^{\max } / \partial b_{i}>0$ and $\partial S_{i}^{\max } / \partial k_{i}>$ 0 , the largest fraction supplier $i$ can offer increases with the price sensitivity and competitive intensity. Furthermore, the fraction supplier $i$ should offer decreases with the price sensitivity and competitive intensity because of $\partial S_{i}^{\mathrm{min}} / \partial b_{i}<0$ and $\partial S_{i}^{\min } / \partial k_{i}<0$.

Lemma 5. When the fraction of the promotional cost sharing $S_{i}(i=1,2)$ is within the appropriate range $\left(S_{i}^{\min }, S_{i}^{\max }\right)$, retailer $i$ 's promotion decisions may change from $N$ to $Y$ as the fraction of the promotional cost sharing $S_{i}$ increases.

According to (8), supply chain $i$ will choose to participate in the promotion if $\pi_{i}^{Y, X_{j}} \geq \pi_{i}^{N, X_{j}}$. Therefore, the lower bound of consumer price sensitivity for supply chain $i$ is formulated as follows:

$$
\begin{aligned}
& L_{i 1}^{I}=\frac{(1-\phi)\left(a_{i}-d_{i} V\right)}{(1-\phi)\left(P_{i}-V\right)-c_{s i}} \text { or } \\
& L_{i 2}^{I}=\frac{(1-\phi) a_{i}}{(1-\phi)\left(P_{i}-V\right)-c_{s i}} .
\end{aligned}
$$

The symbols $L_{i 1}^{I}$ and $L_{i 2}^{I}$ denote the lower bound of consumer price sensitivity when supply chain $j$ chooses to participate in the promotion and when not participating, respectively. It is easy to see that $L_{i 1}^{I}<L_{i 2}^{I}<L_{i 2}^{D}$ and $L_{i 1}^{I}<L_{i 1}^{D}<L_{i 2}^{D}$. Lower intensity of competition (smaller $k_{i}$ ) and higher profit margins can create a competitive advantage for a supply chain.

Lemma 6. When the fraction of the promotional cost sharing is negotiated at $S_{i}(i=1,2)$, then

the incremental profit for supplier $i$ is that $\Delta \pi_{s i}=$ $\pi_{s i}^{Y, X_{j}}-\pi_{s i}^{N, X_{j}}=\left(S_{i}^{\max }-S_{i}\right) q_{i} ;$

the incremental profit for retailer $i$ is that $\Delta \pi_{r i}=\pi_{r i}^{Y, X_{j}}-$ $\pi_{r i}^{N, X_{j}}=\left(S_{i}-S_{i}^{\min }\right) q_{i}$;

the incremental profit for supply chain $i$ is that $\Delta \pi_{i}=$ $\Delta \pi_{s i}+\Delta \pi_{r i}=\left(S_{i}^{\max }-S_{i}^{\min }\right) q_{i}$.

Cost sharing can be achieved if it benefits the supply chain. Let $\alpha(\alpha \geq 0)$ denote each supplier's Nash bargaining power, and let $\beta(\beta \geq 0)$ denote each retailer's Nash bargaining power, $\alpha+\beta=1$. According to Nash's model [41], we obtain the appropriate fraction of the promotional cost sharing which is $S_{i}^{*}=\alpha S_{i}^{\min }+\beta S_{i}^{\max }$.

Theorem 7. The appropriate fraction of promotional cost sharing for supplier $i(i=1,2)$ is $S_{i}^{*}=\alpha S_{i}^{\min }+\beta S_{i}^{\max }$.

The bargaining power between supplier $i$ and retailer $i$ affects the choice of the fraction of promotional cost sharing $S_{i}$. Supplier $i$ shares the smallest fraction of the promotional cost $S_{i}^{\text {min }}$, when she has the complete bargaining power $(\alpha=$ $1, \beta=0$ ). On the contrary, supplier $i$ bears the largest fraction of the promotional cost $S_{i}^{\max }$, when her retailer has the complete bargaining power $(\alpha=0, \beta=1)$.

Theorem 8. When each supplier and her retailer take the cooperative strategy, (a) if $b_{1} \geq L_{12}^{I}$ and $b_{2} \geq L_{22}^{I}$, $(Y, Y)$ is the unique equilibrium; (b) if $b_{1} \in\left[L_{11}^{I}, L_{12}^{I}\right)$ and $b_{2} \in\left[L_{21}^{I}, L_{22}^{I}\right)$, $(Y, Y)$ and $(N, N)$ are the (only) two equilibria, but $(N, N)$ is Pareto optimality; (c) if $b_{1}<L_{11}^{I}$ and $b_{2}<L_{21}^{I}$, $(N, N)$ is the unique equilibrium; (d) if $b_{1}<L_{11}^{I}$ and $b_{2} \geq L_{22}^{I},(N, Y)$ is the unique equilibrium; (e) if $b_{1} \in\left[L_{11}^{I}, L_{12}^{I}\right)$ and $b_{2}<L_{21}^{I}$, $(N, N)$ is the unique equilibrium. (f) If $b_{1} \in\left[L_{11}^{I}, L_{12}^{I}\right)$ and $b_{2} \geq L_{22}^{I}$, $(Y, Y)$ is the unique equilibrium.

Promotion equilibrium decisions may be changed if the suppliers bear the appropriate promotion cost. Under the condition of without considering competition, supply chain $i$ may be better off when supplier $i$ shares the promotional cost and retailer $i$ chooses to participate in the promotion. However, after knowing the action of supply chain $i$, supply chain $j$ may also choose to participate in the promotion for the threat posed by the competitor. As a result, competition between supply chains becomes more intense.

4.3. The Optimal Value of E-Coupon. Now we consider the equilibrium value of e-coupon set by the e-commerce platform. The e-commerce platform sets the value of ecoupon to induce the retailers to participate in the promotion. Based on Lemma 1 and Theorem 8, we have the upper bound of the value of e-coupon:

$$
\begin{aligned}
V_{i 1}^{D} & =\frac{(1-\phi)\left(b_{i} P_{i}-a_{i}\right)-b_{i} w_{i}}{(1-\phi)\left(b_{i}-k_{i} b_{j}\right)}, \\
V_{i 2}^{D} & =\frac{(1-\phi)\left(b_{i} P_{i}-a_{i}\right)-b_{i} w_{i}}{(1-\phi) b_{i}}, \\
V_{i 1}^{I} & =\frac{(1-\phi)\left(b_{i} P_{i}-a_{i}\right)-b_{i} c_{s i}}{(1-\phi)\left(b_{i}-k_{i} b_{j}\right)}, \\
V_{i 2}^{I} & =\frac{(1-\phi)\left(b_{i} P_{i}-a_{i}\right)-b_{i} c_{s i}}{(1-\phi) b_{i}} .
\end{aligned}
$$

The symbols $V_{i 1}^{D}$ and $V_{i 2}^{D}$ denote the maximum value of e-coupon that retailer $i$ can accept when the rival retailer chooses to participate in the promotion and when not participating, respectively. Similarly, $V_{i 1}^{I}$ and $V_{i 2}^{I}$ indicate the 
maximum value of e-coupon that supply chain $i$ can accept when the rival supply chain chooses to participate in the promotion and when not participating, respectively. It is easy to see that $V_{i 2}^{D}<V_{i 1}^{D}<V_{i 1}^{I}$ and $V_{i 2}^{D}<V_{i 2}^{I}<V_{i 1}^{I}$. According to (5), when $\partial \pi_{e} / \partial V=0$, the optimal value of e-coupon for the e-commerce platform is given by

$$
V^{e}=\frac{\sum_{i=1}^{2}\left(b_{i}-k_{i} b_{j}\right) P_{i}-a_{i}}{\sum_{i=1}^{2} 2\left(b_{i}-k_{i} b_{j}\right)}
$$

Theorem 9. The equilibrium value of e-coupon is given by

$$
\begin{aligned}
& V^{*} \\
& = \begin{cases}V^{e}, & \text { if } V^{e} \leq \min \left\{\max \left\{V_{i 2}^{I}, V_{j 2}^{I}\right\}, \min \left\{V_{i 1}^{I}, V_{j 1}^{I}\right\}\right\} ; \\
V_{i 1}^{I}, & \text { if } V_{i 1}^{I}<V_{j 2}^{I}, V^{e} \geq V_{i 1}^{I} ; \\
V_{i 2}^{I}, & \text { if } V_{j 2}^{I}<V_{i 2}^{I}<V_{j 1}^{I}, V^{e} \geq V_{i 2}^{I} .\end{cases}
\end{aligned}
$$

Actually, the value of e-coupon set by the e-commerce platform $V^{*}$ is not optimal for all the parties. The total profits of two supply chains and the e-commerce platform are given by

$$
\begin{aligned}
\pi & =\pi_{e}+\pi_{1}^{X_{1}, X_{2}}+\pi_{2}^{X_{2}, X_{1}} \\
& =\sum_{i=1}^{2}\left(a_{i}+b_{i} V-k_{i} b_{j} V\right)\left(P_{i}-c_{s i}-V\right) .
\end{aligned}
$$

Given consumers' price sensitivity and competitive intensity, all the parties maximize the profit through setting the optimal value of e-coupon, $\partial \pi / \partial V=0$. Therefore, we get the optimal value of e-coupon:

$$
V^{\mathrm{opt}}=\frac{\sum_{i=1}^{2}\left(b_{i}-k_{i} b_{j}\right)\left(P_{i}-c_{s i}\right)-a_{i}}{\sum_{i=1}^{2} 2\left(b_{i}-k_{i} b_{j}\right)} .
$$

Theorem 10. The optimal value of e-coupon for all the parties is $V^{\text {opt }}$; the total profits with the optimal value are higher than the total profits with the equilibrium value, $\pi\left(V^{o p t}\right)>\pi\left(V^{*}\right)$.

The value of e-coupon $V^{\text {opt }}$ was superior to the value set by the e-commerce platform $V^{*}$. Under this condition, both supply chains would be better off and the e-commerce platform would be worse off. The results of Theorem 10 will be explained in Section 5 in detail.

\section{Numerical Examples}

In this section, we present numerical examples which are aimed at illustrating some significant features of the models established in previous sections. In all examples, we set $a_{1}=$ $a_{2}=1000, P_{1}=100, w_{1}=85, c_{s 1}=65, P_{2}=95, w_{2}=82$, $c_{s 2}=65$, and $\phi=0.03$. Given the rival retailer's promotion decisions, a supply chain taking cooperative strategy may outperform those choosing noncooperation. From Table 2, the profits of supplier 1 and retailer 1 increase when the fraction of promotional cost sharing $S_{1}$ is within $\left(S_{1}^{\min }, S_{1}^{\max }\right)$.
TABLE 2: Profits distribution of supply chain 1 under different cost sharing policies.

\begin{tabular}{lcccccc}
\hline$S_{1}$ & $\pi_{s 1}$ & $\pi_{r 1}$ & $\Delta \pi_{s 1}$ & $\Delta \pi_{r 1}$ & $\Delta \pi_{s 1} / \Delta \pi_{1}$ & Equilibrium \\
\hline 0 & 12000 & 7200 & 0 & 0 & 0 & $(N, Y)$ \\
10.17 & 25560 & 7200 & 13560 & 0 & 1 & $(Y, Y)$ \\
12.78 & 18780 & 13980 & 6780 & 6780 & 0.5 & $(Y, Y)$ \\
15.38 & 12000 & 20760 & 0 & 13560 & 0 & $(Y, Y)$ \\
\hline
\end{tabular}

Notes: $V=20, b_{1}=100$, and $d_{1}=20$.

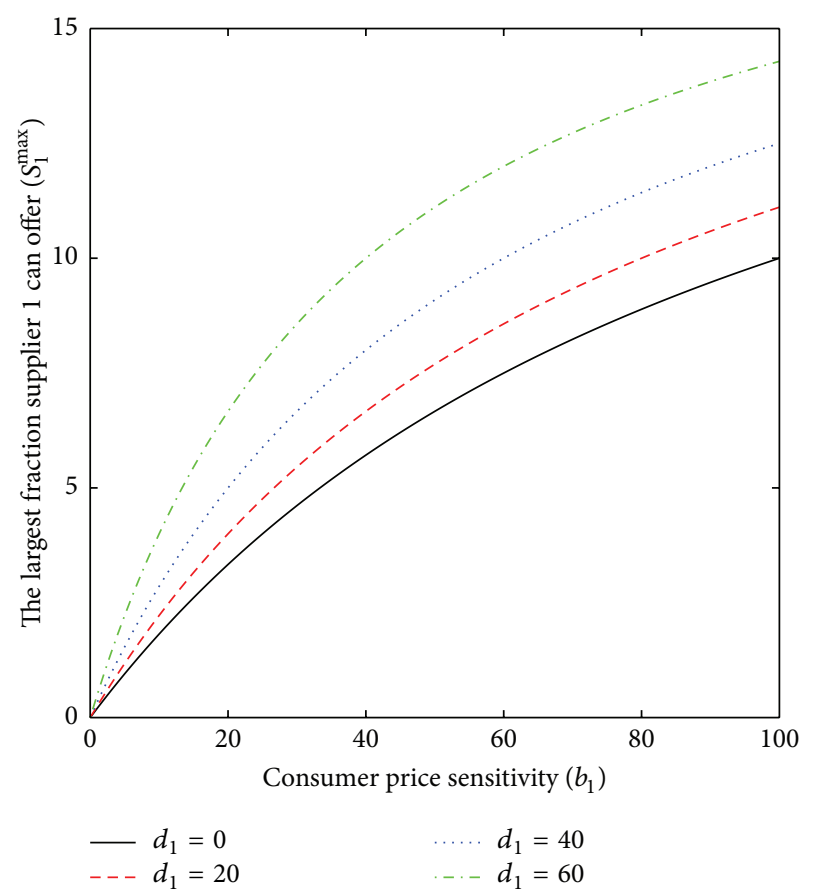

FIGURE 3: The largest fraction of the promotional cost sharing for supplier 1 .

The results show that the suppliers and retailers can benefit from the promotion if the fraction promotional cost sharing is within the appropriate range.

Cost sharing range of supply chains is driven by consumer price sensitivity and competitive intensity. Figure 3 displays the relation between the upper bound of the fraction of the promotional cost sharing and consumer price sensitivity under different intensity of competition. For a given value of e-coupon, the largest fraction of promotional cost sharing offered by supplier $1 S_{1}^{\max }$ increases as consumer price sensitivity increases (larger $b_{1}$ ), even though the products are completely heterogeneous $\left(d_{1}=0\right)$. For any given consumers' price sensitivity, the upper bound of the fraction of the promotional cost sharing will shift upward if competition becomes more intense (larger $d_{1}$ ).

Figure 4 shows that the relation between the lower bound of the fraction of the promotional cost sharing for supplier 1 and consumer price sensitivity under different intensity of competition. We can also see that the smallest fraction of the promotional cost sharing decreases with the consumer 


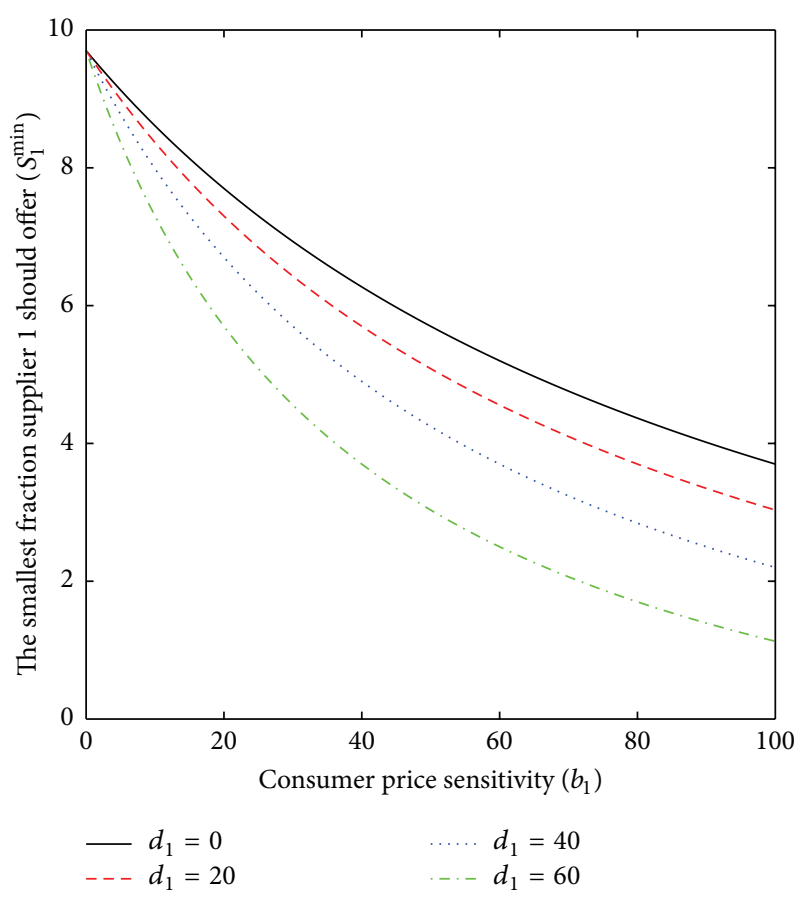

FIGURE 4: The smallest fraction of the promotional cost sharing for supplier 1.

price sensitivity and competition intensity. From Figures 3 and 4 , it is easy to see that the appropriate range $\left(S_{i}^{\min }, S_{i}^{\max }\right)$ becomes wider with the increasing consumer price sensitivity and competitive intensity. This implies that each supplier and her retailer have a wider range for negotiation.

The bargaining power affects the choice of the fraction of promotional cost sharing $S_{i}$. For given competition intensity and the magnitude of markdown, the promotion costs offered by the suppliers depend on consumer price sensitivity and their bargaining power. Figure 5 illustrates the cost sharing policy of supply chain 1 when supplier 1 and retailer 1 have different bargaining power.

The e-commerce platform will capture the profits as much as possible by setting the equilibrium value of e-coupon. Compared with both supply chains that do not to participate in the promotion, supply chain 2 with lower marginal profits may be worse off when supply chain 1 chooses to participate in the promotion. From Figure 6, we can find that the e-commerce platform may be better off when it sets the equilibrium value of e-coupon $V^{*}$. In contrary, both supply chains would be better off if the e-commerce platform sets the optimal value of e-coupon $V^{\text {opt }}$.

The equilibrium value of e-coupon is not optimal for all the parties. Figure 7 displays the difference of the equilibrium value and optimal value. The optimal value of e-coupon is always better than the equilibrium value. The expected profits of both supply chains and the e-commerce platform decrease with the competition intensity. The implication of Figure 7 is that the e-commerce platform should encourage online stores to sell heterogeneity products and eliminate competition.

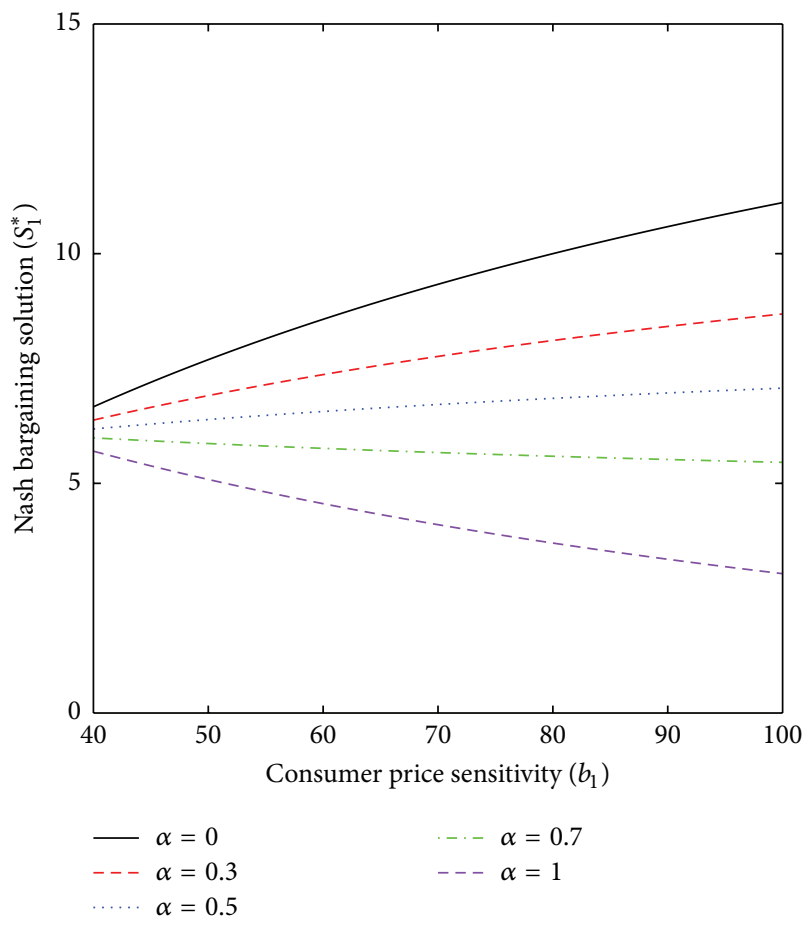

FIGURE 5: Nash bargaining solution for supply chain 1.

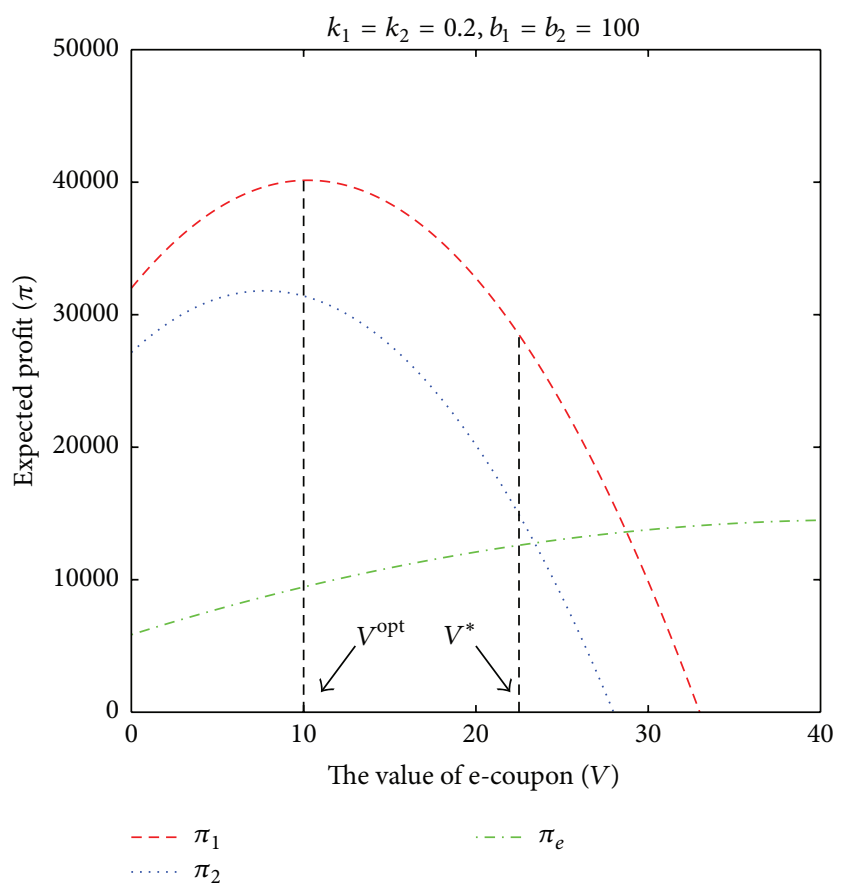

FIGURE 6: Expected profit changes with the value of e-coupon.

\section{Conclusion}

In this paper, we have considered how online cooperative promotion and cost sharing decisions in supply chains depend on consumer price sensitivity, competition intensity, and the magnitude of markdowns. Our results show that (1) the retailers are likely to participate in the promotion if 


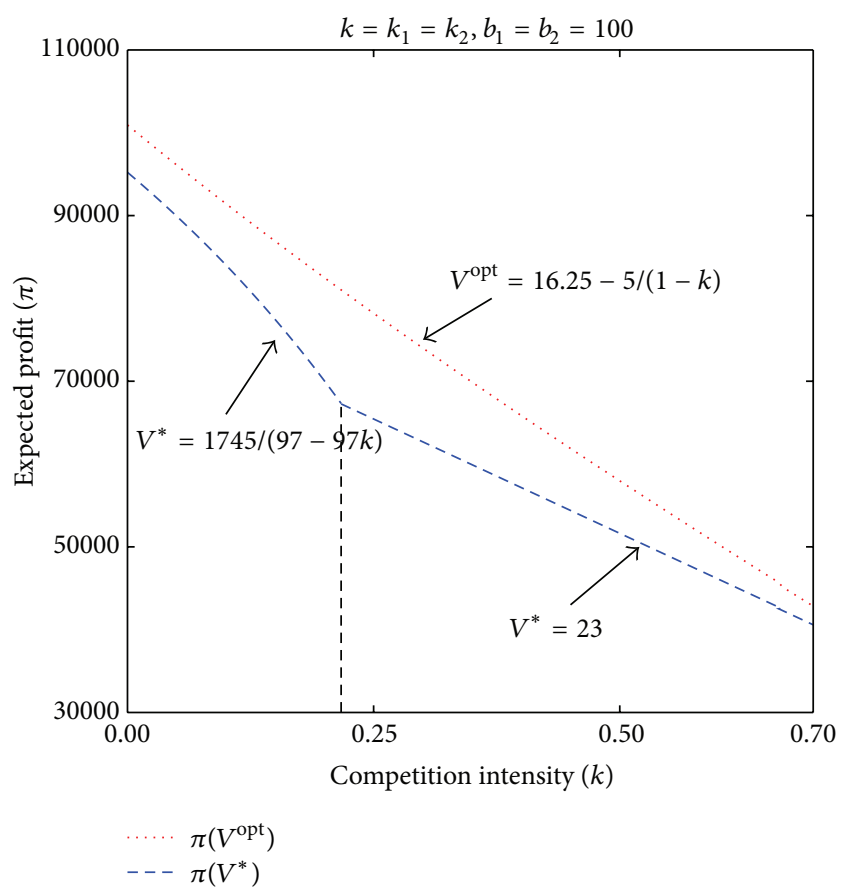

FIGURE 7: Expected profit changes with competition intensity.

consumers become more price-sensitive. However, it does not imply that retailers can benefit from the price promotion; the promotion decision game resembles the classical prisoner's dilemma game. (2) The retailers and suppliers can benefit from the cooperative promotion by designing appropriate cost sharing policy. Cost sharing contract can coordinate the supply chains and improve the supply chain performance. (3) The appropriate range of cost sharing becomes wider as consumers' price sensitivity and competition intensity increase. The bargaining power between suppliers and retailers directly affects the fraction of the promotional cost sharing. (4) The e-commerce platform will capture the most surplus yielded by cooperative promotion through setting the value of e-coupon. The equilibrium value of e-coupon set by ecommerce platform is not optimal for all the parties.

We provide some managerial insights on the coordination of supply chain in the cooperative promotional activity. For a firm, increasing the degree of product heterogeneity is the best way to avoid intense market competition and gain more profits. From a supply chain perspective, the upstream and downstream firms are much more likely to achieve a win-win result in the fierce market competition if they work with each other. In addition, e-commerce platform and retailers may be better off when they make the appropriate cost sharing contract in a cooperative promotion campaign.

Finally, we discuss other future research opportunities. It would be interesting to study the coordination of supply chain consisting of multisupplier and one retailer under supply chain competition when the demand information is imperfect. It would be also interesting to predict the change of consumers' price sensitivity during the online promotion period.

\section{Appendix}

Proof of Lemma 1. Retailer $i(i=1,2)$ will choose to participate in the promotion if and only if $\pi_{r i}^{Y, X_{j}} \geq \pi_{r i}^{N, X_{j}}$; thus we have

$$
\begin{aligned}
& \pi_{r i}^{Y, Y}- \pi_{r i}^{N, Y} \\
&=\left(a_{i}+b_{i} V-k_{i} b_{j} V\right)\left[(1-\phi)\left(P_{i}-V\right)-w_{i}\right] \\
&-\left(a_{i}-k_{i} b_{j} V\right)\left[(1-\phi) P_{i}-w_{i}\right] \\
&= {\left[(1-\phi)\left(P_{i}-V\right)-w_{i}\right] b_{i} V } \\
&-\left(a_{i}-k_{i} b_{j} V\right)[(1-\phi) V] \geq 0 \Longrightarrow \\
& b_{i} \geq L_{i 1}^{D}= \frac{\left(a_{i}-k_{i} b_{j} V\right)[(1-\phi) V]}{\left[(1-\phi)\left(P_{i}-V\right)-w_{i}\right] V} \\
& \pi_{r i}^{Y, N}- \pi_{r i}^{N, N} \\
&=\left(a_{i}+b_{i} V\right)\left[(1-\phi)\left(P_{i}-V\right)-w_{i}+S_{i}\right] \\
&-a_{i}\left[(1-\phi) P_{i}-w_{i}\right] \\
&= {\left[(1-\phi)\left(P_{i}-V\right)-w_{i}+S_{i}\right] b_{i} V } \\
&-a_{i}\left[(1-\phi) V-S_{i}\right] \geq 0 \Longrightarrow \\
& b_{i} \geq L_{i 2}^{D}= {\left[(1-\phi)\left(P_{i}-V\right)-w_{i}+S_{i}\right] V } \\
& {\left[a_{i}\left[(1-\phi) V-S_{i}\right]\right.}
\end{aligned}
$$

when $b_{i} \in\left[L_{i 1}^{D}, L_{i 2}^{D}\right) \Rightarrow \pi_{r i}^{Y, Y} \geq \pi_{r i}^{N, Y}$ and $\pi_{r i}^{Y, N} \leq \pi_{r i}^{N, N}$.

Proof of Theorem 2. According to the analysis of Lemma 1, the equilibriums are obtained as follows. When $b_{1} \geq L_{12}^{D}$ and $b_{2} \geq$ $L_{22}^{D}$, we have $\pi_{r 1}^{Y, Y} \geq \pi_{r 1}^{N, Y}$ and $\pi_{r 2}^{Y, Y} \geq \pi_{r 2}^{N, Y}$; the equilibrium is $(Y, Y)$. When $b_{1} \in\left[L_{11}^{D}, L_{12}^{D}\right)$ and $b_{2} \in\left[L_{21}^{D}, L_{22}^{D}\right)$, we have $\pi_{r 1}^{Y, Y}>\pi_{r 1}^{N, Y}, \pi_{r 2}^{Y, Y}>\pi_{r 2}^{N, Y}, \pi_{r 1}^{Y, N}<\pi_{r 1}^{N, N}$, and $\pi_{r 2}^{Y, N}<\pi_{r 2}^{N, N}$; $(Y, Y)$ and $(N, N)$ are the two equilibria. We can get other equilibriums at the same procedure.

Proof of Theorem 4. The upper bound of the fraction of the promotional cost sharing (the largest fraction supplier $i$ can offer) must satisfy $\pi_{s i}^{Y, X_{j}}=\pi_{s i}^{N, X_{j}}$. Thus, we have

$$
S_{i}^{\max }=\frac{\left(w_{i}-c_{s i}\right) b_{i} V}{a_{i}+b_{i} V-k_{i} b_{j} V}
$$

Also, the lower bound of the fraction of promotional cost sharing (the smallest fraction supplier $i$ should offer) must satisfy $\pi_{r i}^{Y, X_{j}}=\pi_{r i}^{N, X_{j}}$. Thus, we have

$$
S_{i}^{\min }=\frac{(1-\phi)\left[a_{i}-b_{i}\left(P_{i}-V\right)-k_{i} b_{j} V\right] V+b_{i} w_{i} V}{a_{i}+b_{i} V-k_{i} b_{j} V} .
$$


Proof of Theorem 7. To maximize this value, $\left(\Delta \pi_{s i}\right)^{\alpha}\left(\Delta \pi_{r i}\right)^{\beta}$, we build the Lagrange function:

$$
\begin{aligned}
F= & \left(\Delta \pi_{s i}\right)^{\alpha}\left(\Delta \pi_{r i}\right)^{\beta}+\lambda_{1} \Delta \pi_{s i} \\
& +\lambda_{2} \Delta \pi_{r i}+\lambda_{3} S_{i} \Longrightarrow \\
\frac{\alpha}{\Delta \pi_{s i}}= & \frac{\beta}{\Delta \pi_{r i}} \\
\because \Delta \pi_{s i}= & \left(S_{i}^{\max }-S_{i}\right) q_{i}, \\
\Delta \pi_{r i}= & \left(S_{i}-S_{i}^{\min }\right) q_{i} \\
\therefore \alpha\left(S_{i}-S_{i}^{\min }\right)= & \beta\left(S_{i}^{\max }-S_{i}\right) \\
\therefore S_{i}= & \alpha S_{i}^{\min }+\beta S_{i}^{\max } .
\end{aligned}
$$

We have the fraction of promotional cost sharing $S_{i}=$ $\alpha S_{i}^{\min }+\beta S_{i}^{\max }$.

Proof of Theorem 8. Supply chain $i(i=1,2)$ will choose to participate in the promotion if and only if $\pi_{i}^{Y, X_{j}} \geq \pi_{i}^{N, X_{j}}$; thus we have

$$
\begin{aligned}
\pi_{i}^{Y, Y}- & \pi_{i}^{N, Y} \\
= & \left(a_{i}+b_{i} V-k_{i} b_{j} V\right)\left[(1-\phi)\left(P_{i}-V\right)-c_{s i}\right] \\
& -\left(a_{i}-k_{i} b_{j} V\right)\left[(1-\phi) P_{i}-c_{s i}\right] \\
= & {\left[(1-\phi)\left(P_{i}-V\right)-c_{s i}\right] b_{i} V } \\
& -\left(a_{i}-k_{i} b_{j} V\right)(1-\phi) V \geq 0 \Longrightarrow \\
b_{i} \geq L_{i 1}^{I}= & \quad \frac{(1-\phi)\left(a_{i}-k_{i} b_{j} V\right)}{(1-\phi)\left(P_{i}-V\right)-c_{s i}} ; \\
\pi_{i}^{Y, N}- & \pi_{i}^{N, N} \\
= & \left(a_{i}+b_{i} V\right)\left[(1-\phi)\left(P_{i}-V\right)-c_{s i}\right] \\
& -a_{i}\left[(1-\phi) P_{i}-c_{s i}\right] \\
= & {\left[(1-\phi)\left(P_{i}-V\right)-c_{s i}\right] b_{i} V-a_{i}(1-\phi) V \geq 0 \Longrightarrow } \\
b_{i} \geq L_{i 1}^{I}= & \frac{(1-\phi) a_{i}}{(1-\phi)\left(P_{i}-V\right)-c_{s i}},
\end{aligned}
$$

when $b_{i} \in\left[L_{i 1}^{D}, L_{i 2}^{D}\right) \Rightarrow \pi_{i}^{Y, Y} \geq \pi_{i}^{N, Y}$ and $\pi_{i}^{Y, N} \leq \pi_{i}^{N, N}$.

Proof of Theorem 9. When $V_{j 2}^{I} \leq V_{i 2}^{I} \leq V^{*} \leq V_{j 1}^{I} \leq V_{i 1}^{I}$, both supply chains will not to participate in the promotion because $(N, N)$ is Pareto optimality. However, when $V^{*} \leq$ $V_{i 2}^{I} \leq V_{j 1}^{I}$, the dominant strategy for supply chain $i$ is $Y$ and the optimal strategy for supply chain $j$ is $Y$. Hence, the unique equilibrium is $(Y, Y)$. Furthermore, if $V^{e} \geq V_{i 2}^{I}$ and $V_{j 2}^{I}<V_{i 2}^{I}<V_{j 1}^{I}$, e-commerce platform will choose $V_{i 2}^{I}$ as the equilibrium value of e-coupon to induce both supply chains to participate in the promotion.
Proof of Theorem 10. Let $V^{e}=V^{\text {opt }}+A(A>0)$; thus we have $\pi\left(V^{\mathrm{opt}}\right)>\pi\left(V^{e}\right)$ :

$$
\begin{aligned}
\because & \pi\left(V^{\mathrm{opt}}\right)-\pi\left(V^{e}\right)=\sum_{i=1}^{2}\left(a_{i}+b_{i} V^{\mathrm{opt}}-k_{i} b_{j} V^{\mathrm{opt}}\right) \\
& \cdot\left(P_{i}-c_{s i}-V^{\mathrm{opt}}\right) \\
& -\sum_{i=1}^{2}\left[a_{i}+b_{i}\left(V^{\mathrm{opt}}+A\right)-k_{i} b_{j}\left(V^{\mathrm{opt}}+A\right)\right] \\
& \cdot\left(P_{i}-c_{s i}-V^{\mathrm{opt}}-A\right) \\
& =\sum_{i=1}^{2}\left[a_{i}+b_{i}\left(V^{\mathrm{opt}}+A\right)-k_{i} b_{j}\left(V^{\mathrm{opt}}+A\right)\right] \\
& +\sum_{i=1}^{2}\left(k_{i} b_{j}-b_{i}\right)\left(P_{i}-c_{s i}-V^{\mathrm{opt}}\right)>0 \\
\therefore & \pi\left(V^{\mathrm{opt}}\right)>\pi\left(V^{e}\right) .
\end{aligned}
$$

\section{Conflict of Interests}

The authors declare that there is no conflict of interests regarding the publication of this paper.

\section{Acknowledgments}

This research is supported by the Major Program of the National Natural Science Foundation of China (Project no. 71390330), National Natural Science Foundation of China (Projects nos. 71202114, 71172199, and 71202115), and Shandong Independent Innovation and Achievement Transformation Special Fund of China (Project no. 2014ZZCX03302).

\section{References}

[1] Y. Bakos, "The emerging landscape for retail E-commerce," Journal of Economic Perspectives, vol. 15, no. 1, pp. 69-80, 2001.

[2] M. Porter, "Strategy and the internet," Harvard Business Review, vol. 79, no. 3, pp. 62-78, 2001.

[3] M. Wilson-Jeanselme and J. Reynolds, "Growth without profit: explaining the internet transaction profitability paradox," Journal of Retailing and Consumer Services, vol. 12, no. 3, pp. 165-177, 2005.

[4] E. Brynjolfsson, Y. J. Hu, and M. D. Smith, "Consumer surplus in the digital economy: estimating the value of increased product variety at online booksellers," Management Science, vol. 49, no. 11, pp. 1580-1596, 2003.

[5] J. Chu, P. K. Chintagunta, and J. Cebollada, "A comparison of within-household price sensitivity across online and offline channels," Marketing Science, vol. 27, no. 2, pp. 283-299, 2008.

[6] M. Bils, "Pricing in a customer market," The Quarterly Journal of Economics, vol. 104, no. 4, pp. 699-718, 1989.

[7] J. A. Chevalier, A. K. Kashyap, and P. E. Rossi, "Why don't prices rise during periods of peak demand? Evidence from scanner 
data," The American Economic Review, vol. 93, no. 1, pp. 15-37, 2003.

[8] E. J. Warner and R. B. Barsky, "The timing and magnitude of retail store markdowns: evidence from weekends and holidays," The Quarterly Journal of Economics, vol. 110, no. 2, pp. 321-352, 1995.

[9] A. M. Degeratu, A. Rangaswamy, and J. Wu, "Consumer choice behavior in online and traditional supermarkets: the effects of brand name, price, and other search attributes," International Journal of Research in Marketing, vol. 17, no. 1, pp. 55-78, 2000.

[10] G. J. Eskin and P. H. Baron, "Effects of price and advertising in test-market experiments," Journal of Marketing Research, vol. 14, no. 4, pp. 499-508, 1977.

[11] A. Krishna, I. S. Currim, and R. W. Shoemaker, "Consumer perceptions of promotional activity," Journal of Marketing, vol. 55, no. 2, pp. 4-16, 1991.

[12] C. F. Mela, S. Gupta, and D. R. Lehmann, "The long-term impact of promotion and advertising on consumer brand choice," Journal of Marketing Research, vol. 34, no. 2, pp. 248-261, 1997.

[13] G.-R. Chen, "Nonlinear relationship between frequent price discounts and consumers' price sensitivity," Journal of Promotion Management, vol. 19, no. 1, pp. 76-85, 2013.

[14] S. Han, S. Gupta, and D. R. Lehmann, "Consumer price sensitivity and price thresholds," Journal of Retailing, vol. 77, no. 4, pp. 435-456, 2001.

[15] P. K. Kopalle, C. F. Mela, and L. Marsh, "The dynamic effect of discounting on sales: empirical analysis and normative pricing implications," Marketing Science, vol. 18, no. 3, pp. 317-332, 1999.

[16] G. Kalyanaram and R. S. Winer, "Empirical generalizations from reference price research," Marketing Science, vol. 14, no. 3, pp. G161-G169, 1995.

[17] K. Kogan and A. Herbon, "A supply chain under limited-time promotion: the effect of customer sensitivity," European Journal of Operational Research, vol. 188, no. 1, pp. 273-292, 2008.

[18] X. Liang, L. Ma, L. Xie, and H. Yan, “The informational aspect of the group-buying mechanism," European Journal of Operational Research, vol. 234, no. 1, pp. 331-340, 2014.

[19] G. Hua, S. Wang, and T. C. Cheng, "Optimal order lot sizing and pricing with free shipping," European Journal of Operational Research, vol. 218, no. 2, pp. 435-441, 2012.

[20] Y. Liu, H. Li, G. Peng, B. Lv, and C. Zhang, "Online purchaser segmentation and promotion strategy selection: evidence from Chinese E-commerce market," Annals of Operations Research, vol. 233, no. 1, pp. 263-279, 2015.

[21] I. Giannoccaro and P. Pontrandolfo, "Supply chain coordination by revenue sharing contracts," International Journal of Production Economics, vol. 89, no. 2, pp. 131-139, 2004.

[22] S. X. Li, Z. Huang, J. Zhu, and P. Y. K. Chau, "Cooperative advertising, game theory and manufacturer-retailer supply chains," Omega, vol. 30, no. 5, pp. 347-357, 2002.

[23] G. P. Cachon and M. A. Lariviere, "Supply chain coordination with revenue-sharing contracts: strengths and limitations," Management Science, vol. 51, no. 1, pp. 30-44, 2005.

[24] Z. Yao, S. C. Leung, and K. K. Lai, "Manufacturer's revenuesharing contract and retail competition," European Journal of Operational Research, vol. 186, no. 2, pp. 637-651, 2008.

[25] Y.-C. Tsao and G.-J. Sheen, "Effects of promotion cost sharing policy with the sales learning curve on supply chain coordination," Computers \& Operations Research, vol. 39, no. 8, pp. 18721878, 2012.
[26] J. D. Dana and K. E. Spier, "Revenue sharing and vertical control in the video rental industry," The Journal of Industrial Economics, vol. 49, no. 3, pp. 223-245, 2001.

[27] J. Li, S. Wang, and T. C. E. Cheng, "Competition and cooperation in a single-retailer two-supplier supply chain with supply disruption," International Journal of Production Economics, vol. 124, no. 1, pp. 137-150, 2010.

[28] D. Zhang, "A network economic model for supply chain versus supply chain competition," Omega, vol. 34, no. 3, pp. 283-295, 2006.

[29] P. Bhardwaj, "Delegating pricing decisions," Marketing Science, vol. 20, no. 2, pp. 143-169, 2001.

[30] K. S. Moorthy, "Strategic decentralization in channels," Marketing Science, vol. 7, no. 4, pp. 335-355, 1988.

[31] T. W. McGuire and R. Staelin, "An industry equilibrium analysis of downstream vertical integration," Marketing Science, vol. 2, no. 2, pp. 161-191, 1983.

[32] A. T. Coughlan, "Competition and cooperation in marketing channel choice: theory and application," Marketing Science, vol. 4, no. 2, pp. 110-129, 1985.

[33] A. Y. Ha, S. Tong, and H. Zhang, "Sharing demand information in competing supply chains with production diseconomies," Management Science, vol. 57, no. 3, pp. 566-581, 2011.

[34] X. Ai, J. Chen, H. Zhao, and X. Tang, "Competition among supply chains: implications of full returns policy," International Journal of Production Economics, vol. 139, no. 1, pp. 257-265, 2012.

[35] Y. Fang and B. Shou, "Managing supply uncertainty under supply chain Cournot competition," European Journal of Operational Research, vol. 243, no. 1, pp. 156-176, 2015.

[36] D. Wu, O. Baron, and O. Berman, "Bargaining in competing supply chains with uncertainty," European Journal of Operational Research, vol. 197, no. 2, pp. 548-556, 2009.

[37] X. Ai, J. Chen, and J. Ma, "Contracting with demand uncertainty under supply chain competition," Annals of Operations Research, vol. 201, no. 1, pp. 17-38, 2012.

[38] O. C. Demirag, P. Keskinocak, and J. Swann, "Customer rebates and retailer incentives in the presence of competition and price discrimination," European Journal of Operational Research, vol. 215, no. 1, pp. 268-280, 2011.

[39] A. Y. Ha and S. Tong, "Contracting and information sharing under supply chain competition," Management Science, vol. 54, no. 4, pp. 701-715, 2008.

[40] S. Cheng, "Informatization and virtual business," Management Review, vol. 26, no. 7, pp. 3-8, 2014.

[41] J. Nash, "The bargaining problem," Econometrica, vol. 18, pp. 155-162, 1950. 


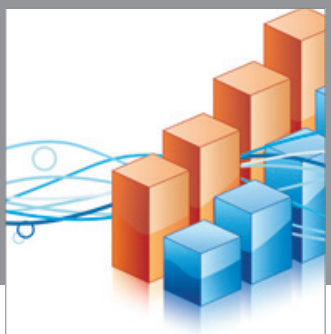

Advances in

Operations Research

vatem alat4

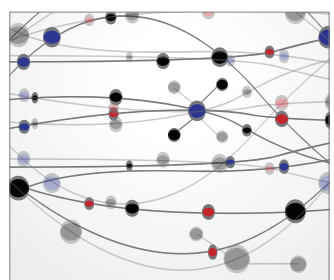

\section{The Scientific} World Journal
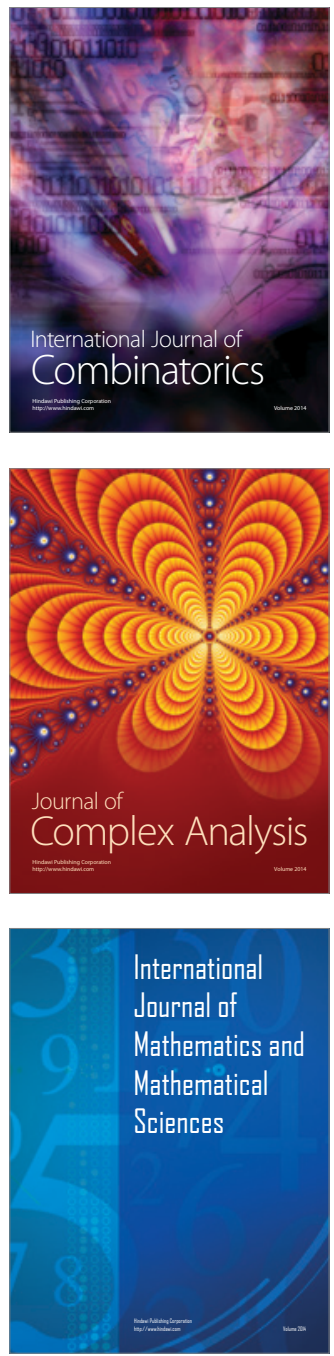
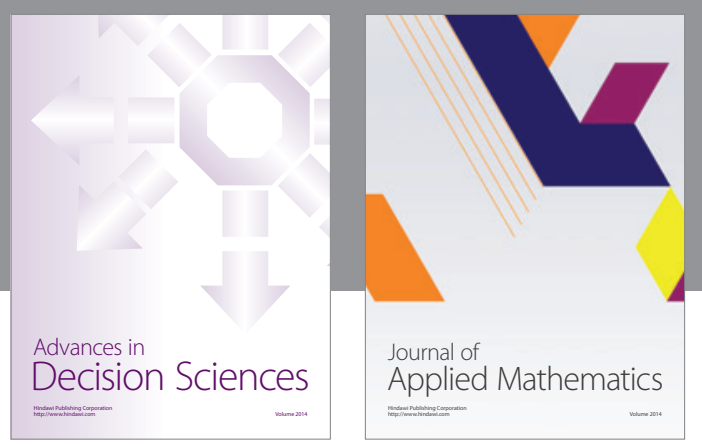

Algebra

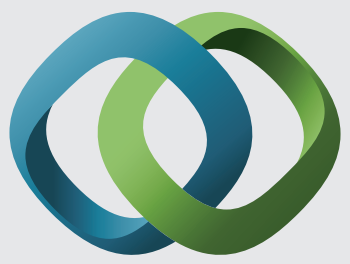

\section{Hindawi}

Submit your manuscripts at

http://www.hindawi.com
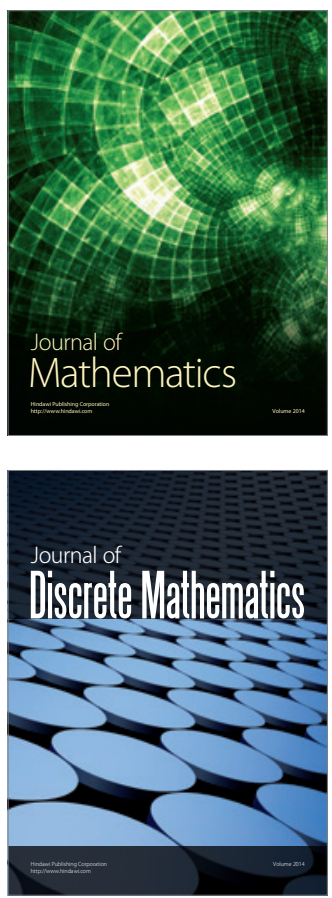

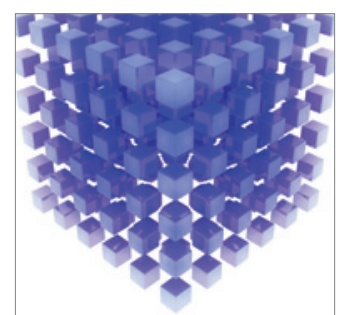

Mathematical Problems in Engineering
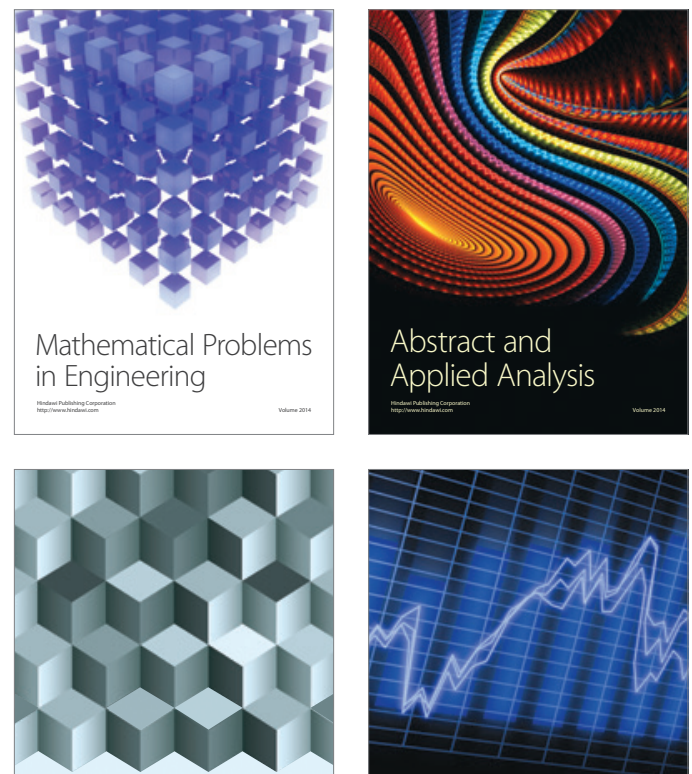

Journal of

Function Spaces

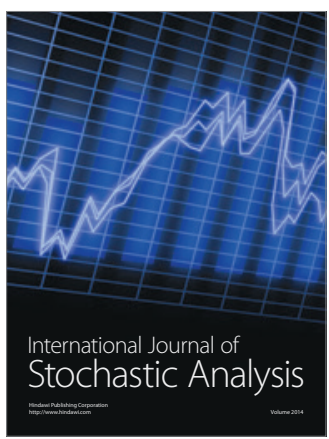

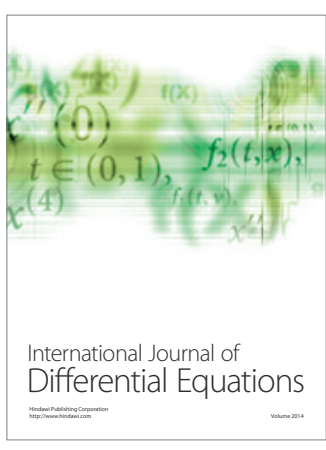
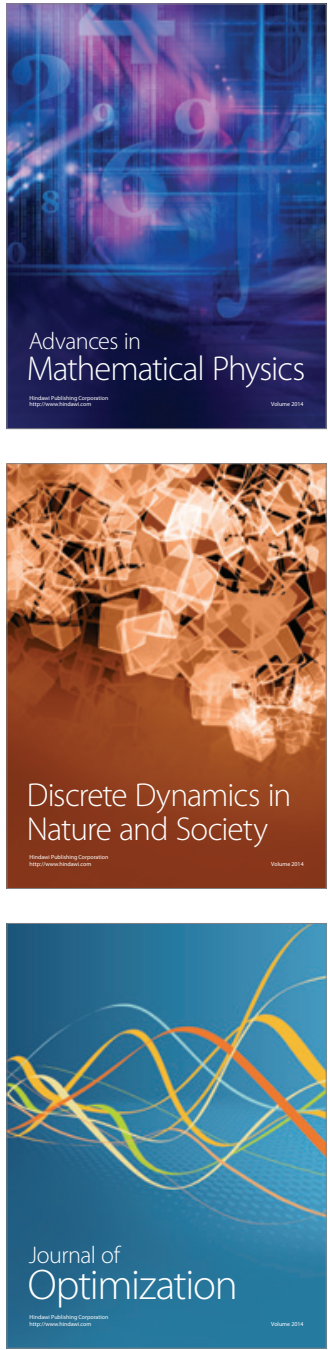